\title{
Trust between Boundary-Spanning Agents: The Role of Relational Competencies
}

\author{
Isabella Hatak, Dietmar Roessl \\ Institute for Small Business Management and Entrepreneurship, WU Vienna University of Economics and \\ Business, Vienna, Austria \\ Email: isabella.hatak@wu.ac.at, dietmar.roessl@wu.ac.at
}

Received September 2014

\begin{abstract}
Against the background of principal-agent and transaction-cost theoretical considerations, this study addresses the question whether relational competencies relate to trust within cooperative relationships, taking into account also situational and personal factors. In its conclusion, the study presents an experimentally confirmed model $(n=282)$ that shows the strong causal relationship between relational competencies and trust allowing boundary-spanning agents to exert influence on the development and maintenance of complex cooperative relationships characterized by long-term objectives.
\end{abstract}

\section{Keywords}

Boundary-Spanning Agents, Competencies, Trust, Cooperation

\section{Introduction}

The mechanisms associated with the development and maintenance of cooperative relationships has received considerable attention because of the recognition that it is possible to increase profitability through long-term relational exchange rather than discrete short-term oriented transactional exchange (see e.g. [1] [2]). Within this domain, a construct that has received particular attention is trust (e.g. [3] [4]).

As the trusting party unilaterally expects the cooperation partner to behave as agreed upon, thus dismissing other behavioral options of the partner [5], the considered behavioral variety is reduced and therefore also the complexity is perceived by the trusting party. Consequently, it has been shown that, by absorbing the complexity of the cooperative relationship, trust can have a positive impact on the performance of cooperating firms (for an overview of studies examining the trust-performance link within interorganizational settings see e.g. [6] and [7]).

Now that the general positive trust effect has been identified, research can move from the question of whether trust relates to the performance of cooperating firms to the identification of specific conditions relevant for the unfolding of the trust-relation between the managers in charge for handling cooperative relationships (boundary-spanning agents [8]). As the link between relational competencies and the development of trust within cooperative relationships has largely been neglected so far, we aim at filling this research gap by addressing the 
question whether so-called relational competencies, that include e.g. communicative and social abilities of the boundary-spanning agents, foster trust within cooperative relationships.

Our study offers the following contributions: By means of a laboratory experiment, whereby the independent variable (relational competencies) was manipulated and other potential influencing variables were controlled for, a causal relationship between relational competencies and trust was clearly detected. The results show that a much more detailed analysis of the conditions of trust in cooperative relations is necessary; thus the paper contributes towards filling exactly the gaps in the trust research map identified by [9].

The paper also has implications for practice: Findings illustrate that a lack of trust manifests itself in an increased orientation towards competition, a higher degree of scrutiny and a reduction in open and truthful information. Although trust does not work in a mechanistic sense, the results indicate the relevance of signalling relational competencies (e.g. ability to communicate and deal with conflict, consistent behaviour, ability to convince others, self-confidence) in an interorganizational context.

\section{Theory and Hypothesis}

\subsection{Trust within Cooperative Relationships}

The advantages of cooperative relationships arise from the functioning coordination of the boundary-spanning agents' behavior within the area of the cooperation. Only if each partner in a cooperative arrangement forgoes short-term opportunism, which "refers to a lack of candor or honesty in transactions, to include self-interest seeking with guile" ([10]: 9), in favor of common long-term objectives, the cooperative relationship can lead to competitive advantages for each cooperation partner. Hence, boundary-spanning agents and the cooperation's success are dependent on the uncertain behavior of their partners [11]. Therefore, the core concept underlying the idea of an opportunistic threat in the context of cooperative relationships is behavioral uncertainty between the boundary-spanning agents. Behavioral uncertainty, which according to [12]: 895 refers to "the potential inherent in a situation for difficulty anticipating and understanding actions", is most relevant in an exchange context [10] as bounded rationality hinders the writing of complete contingent claim contracts [13].

Because behavioral uncertainty cannot be eliminated in complex cooperative relationships [2], boundary-spanning agents need to behave according to their expectation that their cooperation partner will voluntarily refrain from behaving opportunistically [14] —however, as this expectation can be belied (in case of a breach of trust), such behavior, i.e. taking the hold-up risk without protection, constitutes a risky advance performance [5] —and by doing so they perform a trust act [1] [15]-[17]. Trust can therefore be understood as the "willingness of a party to be vulnerable to the actions of another party based on the expectation that the other will perform a particular action important to the trustor, irrespective of the ability to monitor or control that other party" ([9]: 712 [18]: 52).

In the course of developing this trust-related expectation regarding the cooperation partner's behavioral intention, the boundary-spanning agent is confronted with subjective uncertainties concerning the cooperation partner's real preferences and also with objective uncertainties concerning the effects of exogenous factors and behavioral restrictions. Therefore, to put his or her potential trust on a solid basis, the boundary-spanning agent will strive for reducing these subjective uncertainties with the help of additional information [19]. So, with regard to the focus of this paper, the question arises whether the cooperation partner's relational competencies are up to reduce the boundary-spanning agent's subjective uncertainties, thus fostering a risky advance performance on his or her part and therefore enabling the development of trust.

\subsection{Relational Competencies as Trust Drivers within Cooperative Relationships}

Due to the information asymmetries within cooperative relationships [1], the boundary-spanning agent is not only unsure whether the cooperation partner is able to honor his or her trust, but also whether he or she is willing to behave accordingly. The perception of the cooperation partner's relational competencies can now reduce the boundary-spanning agent's subjective uncertainties concerning the willingness of the cooperation partner [20] [21]. Relational competencies refer to the ability of initiating and maintaining exchange relationships. As relational competencies form an abstract entity, we have derived the following indicators by analyzing approaches for measuring relational competencies [22]-[24]: empathy and solidarity, ability to get in contact with others, persuasive power, social-mindedness, ability to communicate, ability to cooperate, ability to handle conflicts. 
Based on his or her relational competencies, the cooperation partner behaves in a trustworthy manner [25] [26] that is, he or she does not misappropriate his or her unrestricted leeway for behavior. Due to this behavior, the boundary-spanning agent expects the partner to refrain from behaving opportunistically also in the future. Therefore, we assume that the cooperation partner's relational competencies have, as additional information, a positive influence on the trust the boundary-spanning agent has for the cooperation partner, which becomes manifest in the amount and correctness of information disclosed and the reduced control intensity employed.

Hypothesis 1: There is a positive relationship between the cooperation partner's relational competencies and the trust the boundary-spanning agent has for the cooperation partner.

Apart from the perceived relational competencies as personal characteristics of the cooperation partner, we assume that certain characteristic traits of the boundary-spanning agent and also situational factors affect the trust the boundary-spanning agent has for the cooperation partner. As the boundary-spanning agent is confronted with limited information in the course of assessing the cooperation partner's trustworthiness in a specific situation, he or she will develop generalized expectations based on past interactions with others [27]. As substitute information such generalized expectations, i.e. the propensity to trust, can then influence the development of trust in a specific cooperative relationship [9] [28].

Hypothesis 2: There is a positive relationship between the boundary-spanning agent's trust propensity and the trust the boundary-spanning agent has for the cooperation partner.

Basically, trust is risky - the cooperation partner has the possibility to misappropriate the boundary-spanning agent's specific investments and, thus, he or she can cause losses on the part of the boundary-spanning agent. Therefore, the risk associated with trust is rooted in the electoral freedom of the cooperation partner between honoring and betraying the boundary-spanning agent's trust [29]. As risk is inherent in trust, we hypothesize that the risk propensity relates positively to the likelihood the boundary-spanning agent will trust the cooperation partner.

Hypothesis 3: There is a positive relationship between the boundary-spanning agent's risk propensity and the trust the boundary-spanning agent has for the cooperation partner.

Moreover, we hypothesize that the risk perception of the concrete situation is negatively related to the likelihood the boundary-spanning agent will deliver a risky advance performance because trusting in such situations goes along with higher risks. The risk perception involves the boundary-spanning agent's beliefs about situation-specific likelihoods of gains and losses, neglecting the influence of the particular cooperation partner (see for example [9] [29]).

Hypothesis 4: There is a negative relationship between the boundary-spanning agent's situational risk perception and the trust the boundary-spanning agent has for the cooperation partner.

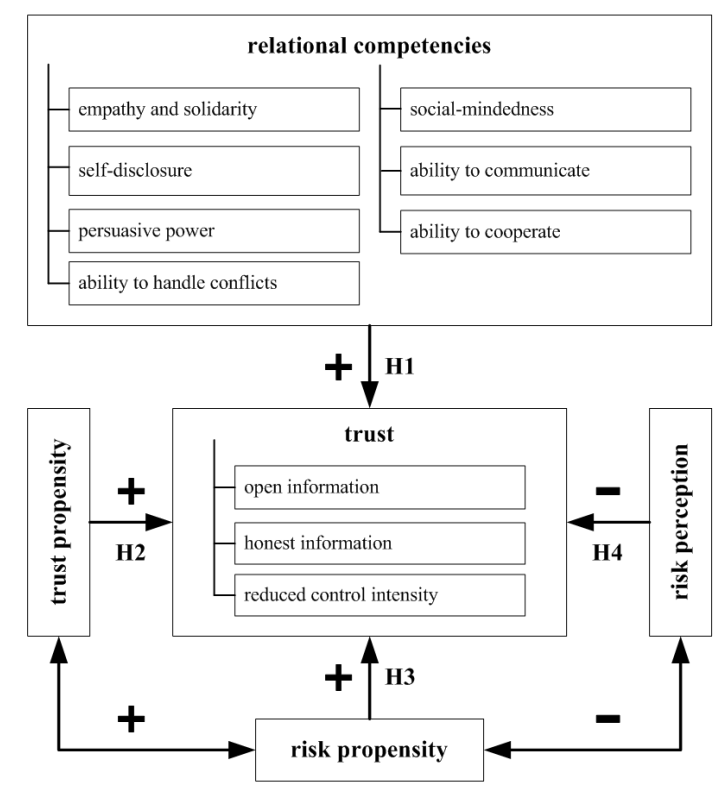

Figure 1. Hypotheses. 


\section{Research Design}

Against the background that our study aims at examining causal relationships, importance is attached to the inferences' internal validity, which entailed the concomitant conceptual decision for a laboratory setting. Nevertheless, while "internal validity is the sine qua non, and while the question of external validity, like the question of inductive inference, is never completely answerable, the selection of designs strong in both typess of validity is obviously our ideal" [30]: 175. Therefore, in order to overcome the limits of laboratory research, we chose to combine the randomized experiment with surveys as proposed by [31].

A total of 282 undergraduate business students (132 males, 150 females) participated in this experiment. Their mean age was 23.30 years $(\mathrm{SD}=3.58)$.

As a first step, the participants came to a classroom on campus, signed in and filled out a consent form. Next, they had to complete a questionnaire which measured their levels of trust propensity $(\alpha=0.925)$ and risk propensity ( $\alpha=0.867)$. The validity and reliability of the trust propensity scale of [32], which is based on Wright man's RPHNS, has been demonstrated in previous research (see for example [33]). The widely used and reliable scale of [34] for measuring risk propensity consists of five items with a 5-point Likert scale ranging from strongly agree to strongly disagree.

After having filled out the survey, the participants were randomly assigned to experimental and control groups, and groups were randomly assigned to conditions. A game-theoretical prisoner's dilemma served as a situational framework: Each participant was presented a written scenario, describing a situation in which they were white wine producers who think about bringing a gift box to market that would consist of one bottle of white wine and one bottle of red wine. In order to realize this idea they could take a cooperative relationship with a red wine producer into consideration. They also received the information that a wine dealer would be interested in exclusively selling the gift box, either consisting of one bottle of red wine and one bottle of white wine, or of two bottles of white wine or two bottles of red wine-depending on the potential of the producers and the quality of their products. Specifically, the wine dealer offered to buy 10,000 bottles in advancewhether the white wine producer shares the amount with the red wine producer (both can sell 5000 bottles) or whether the white wine producer receives the full amount (10,000 bottles; red wine producer: 0 bottles) or whether the red wine producer is awarded the full amount (10,000 bottles; white wine producer: 0 bottles) would depend on the results of a negotiation between the three actors that should take place after the preparatory stage (the announcement of the negotiation worked as a stimulus in order to diminish the "shadow of the future" [35]).

The participants' task was to decide on the strategy they wanted to pursue within the negotiation by studying the given information as to their vineyard, the wine market and the vineyard of the red wine producer. In this regard, the participants were confronted with uncertainty concerning the red wine producer as they received only little information about the latter's vineyard. Thus, in order to be better prepared for the negotiation they could share inside information about their own vineyard (e.g. size, products, and revenue) and the wine market with the red wine producer before the negotiation's beginning, i.e. they had the possibility to transfer correct or wrong information to their potential cooperation partner. Moreover, they could control the information the red wine producer would give them in return (knowing that the red wine producer would be informed about their desire to control his behavior). Trust was therefore measured by summing up the amount of open information, the amount of honest information and the intensity of control (see e.g. [36]).

Following the collection of envelopes and sheets by the experimenter, the participants' perception of the risk inherent in the situation was measured by means of the risk perception scale of [34] which consists of four items with a 5-point Likert scale ranging from strongly agree to strongly disagree $(\alpha=0.768)$.

With regard to the manipulation of the independent variable, the control group and the experimental group were presented the same written scenario, apart from the red wine producer's description: In the experimental group the red wine producer was described as a highly relationally competent person (using the derived indicators of relational competencies), whereas the control group was confronted with a red wine producer that possessed of average relational competencies.

\section{Results}

In order to test the hypotheses as to whether and how strongly pairs of variables are related we used ordinary least square regression. As shown in the Table 1, relational competencies appear to have a statistically significant relationship with trust. Moreover, both risk propensity and trust propensity are significantly related to trust. 
Table 1. Results of regression analysis.

\begin{tabular}{|c|c|c|c|}
\hline & \multicolumn{3}{|c|}{ Trust } \\
\hline & $\beta$ & S.E. & VIF \\
\hline Relational competencies & $0.611^{* * * *}$ & 0.651 & 1.537 \\
\hline Trust propensity & $0.068^{*}$ & 0.053 & 1.050 \\
\hline Risk propensity & $0.134^{* * *}$ & 0.085 & 1.099 \\
\hline Situational risk perception & $-0.108^{* *}$ & 0.134 & 1.065 \\
\hline $\mathrm{R}^{2}$ & 0.78 & & \\
\hline Adjusted $\mathrm{R}^{2}$ & 0.61 & & \\
\hline $\mathrm{F}$ & $89.04^{* * *}$ & & \\
\hline
\end{tabular}

${ }_{\mathrm{p}}^{*}<0.1 ; \stackrel{* *}{\mathrm{p}}<0.05 ;{ }^{* * *} \mathrm{p}<0.01 ;{ }^{* * * *} \mathrm{p}<0.001$

Furthermore, also situational risk perception has a significant effect on trust.

Subsequent Pearson correlation analysis revealed that trust propensity and risk propensity are positively correlated. Against the background that the decision to trust is seen as a risky advance performance, it is comprehensible that a pronounced willingness to trust others goes along with a higher propensity to take risks. Moreover, situational risk perception correlates negatively with risk propensity. Therefore, among cooperators, those who have a low risk propensity tend to perceive a situation as more risky.

Summing up, the hypothesis concerning the strong positive relationship between relational competencies and trust can be corroborated (H1). Regression analysis also revealed that the hypotheses as to the relationship between trust propensity (H2), risk propensity (H3) and situational risk perception (H4) on the one hand and trust on the other hand can be accepted.

\section{References}

[1] Adler, P.S. (2001) Market, Hierarchy and Trust: The Knowledge Economy and the Future of Capitalism. Organization Science, 12, 215-234. http://dx.doi.org/10.1287/orsc.12.2.215.10117

[2] Ring, P.S. and Van de Ven, A. (1992) Structuring Cooperative Relationships between Organizations. Strategic Management Journal, 13, 483-498. http://dx.doi.org/10.1002/smj.4250130702

[3] Das, T.K. and Teng, B.-S. (2003) Partner Analysis and Alliance Performance. Scandinavian Journal of Management, 19, 279-308. http://dx.doi.org/10.1016/S0956-5221(03)00003-4

[4] Currall, St. and Inkpen, A. (2002) A Multilevel Approach to Trust in Joint Ventures. Journal of International Business Studies, 33, 479-495. http://dx.doi.org/10.1057/palgrave.jibs.8491027

[5] Moellering, G. (2002) Perceived Trustworthiness and Inter-Firm Governance: Empirical Evidence from the UK Printing Industry. Cambridge Journal of Economics, 26, 139-160. http://dx.doi.org/10.1093/cje/26.2.139

[6] Mohr, A. and Puck, J. (2013) Revisiting the Trust-Performance Link in Strategic Alliances. Management International Review, 53, 269-289. http://dx.doi.org/10.1007/s11575-012-0145-0

[7] Robson, M.J., Skarmeas, D. and Spyropoulou, St. (2006) Behavioral Attributes and Performance in International Strategic Alliances: Review and Future Directions. International Marketing Review, 23, 585-609. http://dx.doi.org/10.1108/02651330610712120

[8] Zaheer, A., McEvily, B. and Perrone, V. (1998) Does Trust Matter? Exploring the Effects of Interfirm and Interpersonal Trust on Performance. Organization Science, 9, 141-158. http://dx.doi.org/10.1287/orsc.9.2.141

[9] Mayer, R.C., Davis, J.H. and Schoorman, F. (1995) An Integration Model of Organizational Trust. Academy of Management Review, 20, 709-735.

[10] Williamson, O.E. (1975) Markets and Hierarchies: Analysis and Antitrust Implications. Free Press, New York.

[11] Madhok, A. (1995) Opportunism and Trust in Joint Venture Relationships: An Exploratory Study and a Model. Scandinavian Journal of Management, 11, 57-74. http://dx.doi.org/10.1016/0956-5221(94)00029-H 
[12] Krishnan, R., Martin, X. and Noorderhaven, N.G. (2006) When Does Trust Matter to Alliance Performance? Academy of Management Journal, 49, 894-917. http://dx.doi.org/10.5465/AMJ.2006.22798171

[13] Lukas, C. and Schoendube, J.R. (2010) Trust and Adaptive Learning in Implicit Contracts. Review of Managerial Science, 6, 1-32. http://dx.doi.org/10.1007/s11846-010-0045-2

[14] Rousseau, D.M., Sitkin, S.B., Burt, R.S. and Camerer, C. (1998) Not So Different after All: A Cross-Discipline View of Trust. Academy of Management Review, 23, 393-404. http://dx.doi.org/10.5465/AMR.1998.926617

[15] Lavie, D. (2006) The Competitive Advantage of Interconnected Firms: An Extension of the Resource-Based View. Academy of Management Review, 31, 638-658. http://dx.doi.org/10.5465/AMR.2006.21318922

[16] Van de Ven, A.H. and Ring, P.S. (2006) Relying on Trust in Cooperative Inter-Organizational Relationships. In: Bachmann, R. and Zaheer, A., Eds., Handbook of Trust Research, Elgar, Cheltenham, 144-164. http://dx.doi.org/10.4337/9781847202819.00015

[17] Nooteboom, B. (1996) Trust, Opportunism and Governance: A Process and Control Model. Organization Studies, 17, 985-1010. http://dx.doi.org/10.1177/017084069601700605

[18] Roessl, D. (1994) Gestaltung komplexer Austauschbeziehungen—Analyse zwischenbetrieblicher Kooperation. Gabler, Wiesbaden.

[19] McAllister, D.J. (1995) Affect and Cognition-Based Trust as Foundations for Interpersonal Cooperation in Organizations. Academy of Management Journal, 38, 24-58. http://dx.doi.org/10.2307/256727

[20] Mishra, A.K. (1996) Organizational Responses to Crisis: The Centrality of Trust. In: Kramer, R.M. and Tyler, T.R., E., Eds., Trust in Organizations, Sage, Thousand Oaks, 261-287.

[21] Sichtmann, C. (2007) An Analysis of Antecedents and Consequences of Trust in a Corporate Brand. European Journal of Marketing, 41, 999-1015. http://dx.doi.org/10.1108/03090560710773318

[22] Erpenbeck, J. and Heyse, V. (2007) Die Kompetenzbiographie. Waxmann, Muenster.

[23] Kauffeld, S., Grote, S. and Frieling, E. (2007) Das Kasseler-Kompetenz-Raster. In: Erpenbeck, J. and von Rosenstiel, L., Eds., Handbuch Kompetenzmessung, Schaeffer-Poeschl, Stuttgart, 224.

[24] Edwards, M.R. and Ewen, A.J. (1996) 360-Feedback: The Powerful New Model for Employee Assessment \& Performance Improvement. AMACOM, New York.

[25] Argyle, M. (1969). Social Interaction. Methuen, London.

[26] Docherty, P. and Marking, C. (1997) Understanding Changing Competence Demands. In: Docherty, P. and Nyhan, B., Eds., Human Competence and Business Development. Emerging Patterns in European Companies, Springer, London, 19-42. http://dx.doi.org/10.1007/978-1-4471-0915-0_2

[27] Rotter, J.B. (1967) A New Scale for the Measurement of Interpersonal Trust. Journal of Personality, 35, 651-665. http://dx.doi.org/10.1111/j.1467-6494.1967.tb01454.x

[28] Currall, St. and Judge, T.A. (1995) Measuring Trust between Organizational Boundary Role Persons. Organizational Behavior and Human Decision Processes, 64, 151-170. http://dx.doi.org/10.1006/obhd.1995.1097

[29] Coleman, J.S. (1990) Foundations of Social Theory. Harvard University Press, Cambridge.

[30] Campbell, D.T. and Stanley, J.C. (1963) Experimental and Quasi-Experimental Designs for Research. Rand McNally, Chicago.

[31] Fehr, E., Fischbacher, U., Schupp, J., von Rosenbladt, B. and Wagner, G.G. (2003) A Nationwide Laboratory Examining Trust and Trustworthiness by Integrating Behavioural Experiments into Representative Surveys. Centre for Economic Policy Research, London.

[32] Costa, A.C. (2000) A Matter of Trust: Effects on the Performance and Effectiveness of Teams in Organizations. Riddekerk Print, Tilburg.

[33] Spaeth, J.F. (2008) Interpersonelles Vertrauen in Organisationen. Peter Lang, Frankfurt.

[34] Sitkin, S.B. and Weingart, L.R. (1995) Determinants of Risky Decision-Making Behavior. Academy of Management Journal, 38, 1573-1592. http://dx.doi.org/10.2307/256844

[35] Axelrod, R. (1984) The Evolution of Cooperation (Vol. 2). Basic Books, New York.

[36] O’Reilly III, C.A. and Roberts, K.H. (1974) Information Filtration in Organizations: Three Experiments. Organizational Behavior and Human Performance, 11, 253-265. http://dx.doi.org/10.1016/0030-5073(74)90018-X 